\title{
A limentação na escola como forma de atender às recomendações nutricionais de alunos dos Centros Integrados de Educação Pública (CIEPS)
}

\author{
School meal programs as a means to meet \\ nutritional requirements for students in the \\ Integrated Public School Centers (CIEPS)
}

Marina Vieira da Silva 1

\footnotetext{
1 Escola Superior de Agricultura "Luiz de Queiróz", Campus USP/Piracicaba. Av. Pádua Dias 11 C.P. 9, Piracicaba, SP 13418-900, Brasil.
}

\begin{abstract}
A bstract This study evaluates food intake of 244 children between ages 7-13 years using records of ingested foods on three non-consecutive days. The study analyzes energy and nutrient adequacy based on standards for the Brazilian population. Diet was generally found to be energydeficient: meals consumed at the CIEPs met less than $70 \%$ of the requirement. On the other hand, protein was well above recommended levels. Worthy of note was the adequacy of meals in the CIEPs as to vitamin A, thiamin, riboflavin, and niacin, as well as the surprising adequacy of ascorbic acid, resulting from the frequent presence of citrus fruits in school meals. Except for older students, all schoolchildren studied had greater than $90 \%$ minimum iron intake. As for cal cium, again except for older ones, consumption was $100 \%$ or more of minimum required levels. Results showed the need to correct flaws in the nutritional content of school meals, which are central to dietary intake for CIEP students.

Key words School Feeding; Dietary Intake; Food Consumption; Nutrition; Child Health
\end{abstract}

Resumo Avalia-se o consumo alimentar de 244 crianças amostradas utilizando-se o regi stro dos al imentos por el as ingeridos, durante três dias não consecutivos da semana. Analisa-sea adequação de energia e nutrientes de acordo com o padrão definido para a população brasileira. Observa-se que a di eta dos escol ares revela-se, em média, defici ente em energia: as refeições consumidas no âmbito dos CIEPs não al cançam 70\% de adequação. Verifica-se que, inversamente, o conteúdo protéi co das dietas apresenta-se mui to acima do preconizado. Ressalta-se a satisfatória adequação das refeições consumidas no âmbi to dos CIEPs quanto às vitaminas A, tiamina, riboflavina e niacina. Merece destaque a surpreendente adequação das di etas dos escol ares em relação ao ácido ascórbico. Contribui para esse resultado a presença freqüente de frutas cítricas nas refei ções da escola. Com relação ao ferro, constata-seque, com exceção dos escolares mais vel hos, todos os demais exi bem di etas que ultrapassam 90\% de adequação. Quanto ao cál cio, nota-se que as dietas da mai oria (exceto a dos alunos de mai or idade) al cançam $100 \%$ de adequação. Resultados do estudo mostram necessi dade de corrigir fal has do conteúdo nutricional das refeições distribuídas na escola, pois as mesmas constituem parte fundamental do consumo alimentar dos alunos dos CIEPs.

Palavras-chave Alimentação Escolar; Consumo deAlimentos; Nutrição; Saúdelnfanti I 


\section{Introdução}

Nas últimas décadas, as transformações de ordem econômica, social e demográfica pelas quais passou a sociedade brasileira afetaram consideravelmente o perfil nutricional e educacional da população.

Ao examinar a literatura especializada, verifica-se que a produção intelectual voltada a análise da alimentação de crianças em idade escolar e adolescentes é reduzida, justificando a realização de estudos tendo o referido grupo como alvo.

Especificamente quanto ao sistema escolar público, pesquisas relativas aos aspectos quantitativos e qualitativos revelam significativo déficit, sugerindo que a nobre missão de "ensinar tudo a todos" continua urgente e preocupante (FIBGE, 1989; Pipitone, 1991).

Desse modo, o propósito de cumprir o artigo constitucional que garante a educação como direito de cada um e dever do Estado, somado ao caótico quadro da educação no País, tem proporcionado o aparecimento de inúmeras e diferentes experiências educacionais que surgem com a promessa de solução à crise imposta ao sistema educacional vigente.

$\mathrm{Na}$ metade da década dos 80 , a proposta pedagógica da escola de tempo integral surge com força no cenário da educação brasileira, através da experiência dos Centros Integrados de Educação Pública - CIEPs, implantados no governo de Leonel Brizola sob coordenação, na época, do secretário estadual de educação, o antropólogo Darcy Ribeiro.

Experiência similar à do governo do Rio de Janeiro surge no Estado de São Paulo, especificamente no Município de Americana. A partir de 1990, por intermédio da administração municipal, foi iniciada a implantação de quatro CIEPs.

A proposta de tempo integral traz para o interior da escola uma série de funções supletivas à função pedagógica institucional que podem ser exemplificadas pelas atividades de curar, proteger, alimentar, entre outras.

Acredita-se que não há por que ser contra as funções supletivas, relacionadas à assistência médica, alimentar e a outras, desde que se constituam viabilizadoras da própria função pedagógica.

De acordo com Ribeiro (1986), a assistência alimentar, nos CIEPs, integra-se às demais atividades de atenção primária à saúde e "procura incorporar às refei ções diárias das crianças alimentos de al to valor nutritivo".

A proposta básica do plano alimentar consiste no fornecimento de três refeições diárias que devem ser planejadas levando em consideração as principais carências nutricionais do grupo atendido.

O conjunto das três refeições tem a finalidade de fornecer 2.500 quilocalorias. Note-se que não há, no plano alimentar dos CIEPs, qualquer referência às recomendações nutricionais quanto aos nutrientes (proteína, vitaminas e minerais), às distintas faixas etárias e também ao sexo dos escolares.

Tendo em vista o papel fundamental da alimentação na definição do estado de saúde das crianças e a importância do programa de alimentação para viabilização da escola de tempo integral, o presente trabalho pretende contribuir para a análise do consumo alimentar de escolares matriculados nos CIEPs de Americana, Estado de São Paulo, com ênfase na análise das refeições consumidas no âmbito destes Centros Integrados. A pesquisa objetiva, também, a avaliação da adequação do consumo diário de calorias e nutrientes conforme a faixa etária da criança, a análise do consumo de alimentos em nível da escola integral e domiciliar e a associação entre renda familiar e consumo de energia e nutrientes.

\section{Metodologia}

O estudo foi desenvolvido no Município de Americana, localizado na Região Administrativa de Campinas, que possui 144 km² de extensão territorial e 153.840 habitantes. A taxa de urbanização da cidade é de $99,88 \%$ e a densidade demográfica, 1.067,91 hab/ km² (Seade, 1991).

O Município é um dos maiores produtores de tecidos do País; $50 \%$ de todo ramo industrial, que atualmente conta com 958 empresas, são de atividade têxtil. Da outra metade das indústrias de transformação, 25\% também estão ligadas ao ramo. As indústrias de tecelagem são as maiores empregadoras de mão-de-obra da cidade (Seade, 1993).

Deve-se destacar que Americana foi a única cidade, no Estado de São Paulo, a implantar as escolas de tempo integral, destinadas ao atendimento de crianças da faixa etária de sete a 14 anos. Atualmente estão em funcionamento quatro Centros Integrados de Educação Pública CIEPs, localizados em bairros onde se concentra grande contingente de famílias de baixa renda.

Para a execução da pesquisa, realizou-se, junto à diretoria das quatro escolas, levantamento preliminar, visando à obtenção de informações relativas ao número de alunos matriculados em cada unidade. Levantaram-se tam- 
bém os dados referentes à identificação da criança (nome completo, sexo, data de nascimento e endereço).

Uma vez identificadas as 2.579 crianças, foi feita a classificação em sete grupos de idade em cada um dos CIEPs, distinguindo-as por sexo. Assim, obteve-se: 4 (número de CIEPs) $x 7$ (número de grupos de idade) $\times 2$ (sexos: masculino e feminino) $=56$ estratos.

Para a composi ção da amostra estratificada proporcional, optou-se pelo sorteio de $10 \%$ dos escolares matriculados, obtendo-se, assim, 257 crianças. Esse procedimento garante que a distribuição das crianças conforme CIEPs, sexo e grupo etário represente sua distribuição na população considerada.

O consumo alimentar dos escolares foi obtido pelo registro dos alimentos ingeridos pela criança durante três dias da semana não consecutivos.

Esse procedimento visou conhecer a variação semanal e também minimizar as possíveis diferenças que pudessem existir nos hábitos alimentares. Sábados e domingos não foram considerados porque, nesses dias, os CIEPs não mantêm atividades.

Para a conversão em gramas dos alimentos registrados em medidas caseiras, utilizaram-se os pesos destas medidas adotados no Programa de Apoio à Decisão em Nutrição (versão 2.0), desenvolvido pelo Centro de Informática em Saúde da Universidade Federal de São Paulo (Escola Paulista de Medicina).

Para o registro do consumo de alimentos, em nível doméstico, dos escolares de sete e oito anos de idade, optou-se por solicitar as informações à mãe ou à pessoa responsável pela alimentação. Esta preocupação é justificada por limitações da memória das crianças, principalmente das mais jovens, que com grande freqüência, erram detalhes e confundem eventos imaginários com reais (Madden et al., 1976).

Com base nas informações relativas às quantidades dos alimentos, foi possível elaborar cálculos visando à avaliação da ingestão de cal orias e nutrientes. Para tanto, utilizou-se a Tabela de Composição de Alimentos do Instituto Brasileiro de Geografia e Estatística - FIBGE (1977). A fim de obter a adequação média da dieta dos escolares investigados, foram adotadas como parâmetro as recomendações diárias de energia e nutrientes propostas por Martins \&Hidalgo (1983), adaptando-as para o grupo investigado, conforme apresentado na Tabela 1.

Serão considerados adequados os valores de energia e nutrientes da dieta dos escolares

Tabela 1

Recomendações de energia e nutrientes, adaptadas por idade e sexo daquelas propostas para a população brasileira*.

\begin{tabular}{|c|c|c|c|c|c|c|c|c|c|c|}
\hline $\begin{array}{l}\text { Idade } \\
\text { (anos) }\end{array}$ & Sexo & $\begin{array}{r}\text { Energia } \\
(\text { kcal)** }\end{array}$ & $\begin{array}{c}\text { Proteína } \\
\qquad(\mathrm{g})^{* *}\end{array}$ & $\begin{array}{c}\text { Vitamina } A \\
(\mu E R)\end{array}$ & $\begin{array}{l}\text { Tiamina } \\
\text { (mg) }\end{array}$ & $\begin{array}{l}\text { Riboflavina } \\
\text { (mg) }\end{array}$ & $\begin{array}{l}\text { Niacina } \\
(\mathrm{mg})\end{array}$ & $\begin{array}{c}\text { Ácido ascórbico } \\
(\mathrm{mg})\end{array}$ & $\begin{array}{l}\text { Cálcio } \\
\text { (mg) }\end{array}$ & $\begin{array}{r}\text { Ferro } \\
\text { (mg) }\end{array}$ \\
\hline \multirow[t]{2}{*}{7} & $M$ & 1.900 & 39 & 400 & 0,76 & 1,05 & 12,54 & 20 & 450 & 10 \\
\hline & $\mathrm{F}$ & 1.750 & 38 & 400 & 0,70 & 0,96 & 11,55 & 20 & 450 & 10 \\
\hline \multirow[t]{2}{*}{8} & $M$ & 2.000 & 42 & 400 & 0,80 & 1,10 & 13,20 & 20 & 450 & 10 \\
\hline & $F$ & 1.890 & 41 & 400 & 0,76 & 1,04 & 12,47 & 20 & 450 & 10 \\
\hline \multirow[t]{2}{*}{9} & $M$ & 2.200 & 44 & 400 & 0,88 & 1,21 & 14,52 & 20 & 450 & 10 \\
\hline & $\mathrm{F}$ & 2.100 & 45 & 400 & 0,84 & 1,16 & 13,86 & 20 & 450 & 10 \\
\hline \multirow[t]{2}{*}{10} & $M$ & 2.350 & 48 & 575 & 0,94 & 1,29 & 15,51 & 20 & 650 & 10 \\
\hline & $\mathrm{F}$ & 2.250 & 48 & 575 & 0,90 & 1,24 & 14,85 & 20 & 650 & 10 \\
\hline 11 & $\mathrm{~F}$ & 2.300 & 51 & 575 & 0,92 & 1,27 & 15,18 & 20 & 650 & 10 \\
\hline \multirow[t]{2}{*}{12} & $M$ & 2.700 & 57 & 575 & 1,10 & 1,49 & 17,82 & 20 & 650 & 10 \\
\hline & $\mathrm{F}$ & 2.400 & 54 & 575 & 0,96 & 1,32 & 15,84 & 20 & 650 & 10 \\
\hline \multirow[t]{2}{*}{13} & $M$ & 2.750 & 61 & 725 & 1,21 & 1,51 & 18,15 & 30 & 650 & 18 \\
\hline & $\mathrm{F}$ & 2.500 & 81 & 725 & 1,00 & 1,38 & 16,50 & 30 & 650 & 24 \\
\hline
\end{tabular}

\footnotetext{
Martins \& Hidalgo (1983)

** Foram feitos arredondamentos no algarismo referente a dezenas de calorias e a gramas de proteínas, tendo em vista que variações desta ordem de grandeza não têm significado prático.
} 
que atingirem $100 \%$ das recomendações nutricionais.

Para a coleta das informações relativas à renda familiar, realizou-se entrevista, na própria escola, com a mãe ou responsável. Obteve-se a renda familiar considerando-se a soma dos rendimentos de cada morador que contribuísse para o conjunto das despesas da casa. Foram incluídos rendimentos provenientes de pensão, aposentadoria, aluguel. A renda per capita foi obtida dividindo-se o resultado pelo número de moradores.

Para elaborar as análises de regressão utilizou-se o programa Statistical Analysis System SAS.

\section{Resultados}

É importante lembrar que a amostra inicial constituiu-se de 257 crianças pertencentes aos quatro CIEPs de Americana. Foi possível obter informações do consumo alimentar de 244 crianças, que representam $94,9 \%$ do total amostrado.

Tendo como base as informações contidas nos formulários de registro de alimentos, elaborou-se a Tabela 2, que mostra a percentagem da presença de determinados alimentos, nas diferentes refeições do dia (desjejum, almoço e jantar) servidas nos CIEPs, e do consumo de alimentos em nível domiciliar e/ ou em outros estabelecimentos (ceia).

Verifica-se que os produtos lácteos, representados quase que exclusivamente pelo leite, aparecem em $83,6 \%$ dos desjejuns e em menor proporção (7,6\%) nas ceias. Alimentos como o queijo e o iogurte são pouco freqüentes, sendo mencionados somente nas refeições realizadas fora da escola.

Analisando-se a presença de carnes nas refeições, chama a atenção o consumo de aves (especificamente o frango): $41,3 \%$ nos almoços, $13,9 \%$ nos jantares e $5,8 \%$ nas ceias.

É interessante ressaltar que a freqüência das carnes de porco e peixe é observada exclusivamente nas refeições fornecidas nos CIEPs.

Com relação ao arroz, constata-se que o mesmo está presente em $85,7 \%$ e $22,9 \%$ dos almoços e jantares, respectivamente. Verifica-se também que o mesmo aparece em $21,3 \%$ das ceias.

Enfatiza-se que o feijão é a fonte mais importante de ferro da dieta da população brasileira. Note-se que esse alimento aparece em $79,0 \%$ do almoço. As proporções decrescem para $22,9 \%$ no jantar e a $6,9 \%$ nas refeições domiciliares.
Quanto ao pão, nota-se que houve registro em $63,8 \%$ do desjejum e 35,0\% nas citações da ceia e que, com relação aos embutidos, destaca-se a presença da salsicha no almoço $(9,0 \%)$ e no jantar (4,9\%). A mortadela aparece em 11,1\% das ceias, tendo sido o embutido mais citado.

Merece destaque a presença de alface e tomate na refeição principal (almoço) oferecida nos CIEPs. Observe que a frequência desses alimentos é substancialmente menor nas refeições domiciliares.

Ainda de acordo com a Tabela 2, constatase que as frutas, especialmente a laranja e a banana, destacam-se entre as demais, principalmente nas refeições fornecidas pelos Centros Integrados. Quando se examinam as refeições domiciliares, nota-se redução nessa proporção (menos que 3,0\% de citações).

Nas Tabelas 3 e 4, verificam-se os dados referentes à adequação média do consumo de energia e nutrientes ocorrido no âmbito dos CIEPs e domiciliar, respectivamente. Nota-se que a ingestão calórica constitui-se maior problema para os escolares, principalmente entre os que pertencem aos estratos de maior idade.

Quanto à proteína, observe-se que, para todas as faixas de idade, a alimentação recebida nos CIEPs ultrapassa os valores recomendados para o grupo.

Em relação à energia, verifica-se que a contribuição percentual média das refeições distribuídas na escola é muito baixa. Os piores índices foram obtidos para os grupos de nove a dez (59\%) e com 13 anos ou mais (56\%).

No que diz respeito às vitaminas, situação bastante favorável é observada com relação a vitamina A. Com exceção dos escolares mais velhos, a alimentação recebida nos CIEPs supera o recomendado.

Quanto às vitaminas do Complexo B, particularmente, os resultados apontam para a menor contribuição (refeições servidas no âmbito dos (IEPs) da niacina. $\mathrm{O}$ atendimento feito por meio das refeições dos CIEPs não chegou a atingir $100 \%$ para nenhuma das faixas de idade estudadas.

No caso dos alunos dos Centros Integrados de Americana, mesmo não alcançando $100 \%$ de adequação de niacina pela alimentação da escola, a dieta não é deficiente em decorrência do razoável consumo do nutriente em nível domiciliar.

Outro achado relevante é a surpreendente adequação da dieta com relação ao ácido ascórbico. Para todas as faixas de idade estudadas, verificou-se adequação muito superior a $100 \%$.

No que se refere ao cálcio, a dieta global pode ser considerada bastante razoável. Vale des- 
tacar que a alimentação oferecida nos CIEPs contribui com mais de $100 \%$ das recomendações para as crianças com até dez anos de idade. A menor adequação é verificada para os escolares de maior idade.

Ainda com relação aos minerais, neste estudo foi possível constatar que, com exceção dos escolares mais velhos (60,6\%), todos os demais possuem dietas que ultrapassam $90 \%$ do valor recomendado do ferro.

Quanto ao comportamento do rendimento familiar per capita, os dados obtidos para os 228 escolares, para os quais se dispõe da informação, mostram os seguintes resultados: 163 escolares, representando $71,49 \%$ da amostra, apresentam renda familiar per capita inferior a $\mathrm{R} \$ 75,00$, e 48 ( $21,05 \%$ do total) possuem rendimento per capita inferior ou igual a $R \$ 25,00$.

No estrato dos rendimentos mais elevados, verifica-se que somente 65 alunos (28,5\%) possuem renda familiar per capita igual ou acima a $R \$ 75,00$.

Quanto à relação entre o consumo e renda familiar per capita dos escolares, os nutrientes cuja adequação se mostra estatisticamente associada ao logaritmo da renda per capita são: energia $(r=0,114)$, proteína $(r=0,134)$, ferro $(r=0,211)$, riboflavina $(r=0,116)$, niacina $(r=0,182)$ e ácido ascórbico $(r=0,166)$. No caso da niacina, do ácido ascórbico e do ferro, a correlação da adequação com renda per capita é estatisticamente significativa ao nível de $5 \%$.

As respectivas equações de regressão são apresentadas a seguir. Note-se que o logaritmo da renda per capita é indicado por Y. Os percentuais de adequação do consumo de energia, proteína, ferro, riboflavina, niacina e ácido ascórbico são representados, respectivamente, por: AENER, APROT, AFERR, ARIBO, ANIAC e AAASC. O valor do teste t para a hipótese da nulidade do parâmetro é apresentado entre parênteses, abaixo do coeficiente, sendo assinalado com dois asteriscos se for significativo ao nível de $5 \%$ e com um asterisco se for significativo apenas ao nível de $10 \%$.

$$
\begin{array}{rr}
\text { AENER }=61,5+5,13 Y \\
& \left(5,35^{* *}\right) \quad\left(1,73^{*}\right) \\
\text { APROT }= & 104,9+11,24 Y \\
& \left(4,89^{* *}\right) \quad\left(2,04^{* *}\right) \\
\text { AFERR }=45,0+16,16 Y \\
& \left(2,33^{* *}\right) \quad\left(3,25^{* *}\right) \\
\text { ARIBO }= & 100,6+13,28 Y \\
& \left(3,44^{* *}\right) \quad\left(1,76^{*}\right) \\
\text { ANIAC }=53,6+13,53 Y \\
& \left(2,84^{* *}\right) \quad\left(2,79^{* *}\right) \\
\text { AAASC }= & 194,5+40,70 Y \\
& \left(3,12^{* *}\right) \quad\left(2,53^{* *}\right)
\end{array}
$$

\begin{tabular}{|c|c|c|c|c|}
\hline \multirow[t]{2}{*}{ Alimentos } & \multirow[b]{2}{*}{ Desjejum* } & \multicolumn{3}{|c|}{ Refeição } \\
\hline & & $\begin{array}{c}\text { Cieps } \\
\text { Almoço* }\end{array}$ & J antar* & $\begin{array}{c}\text { Domiciliares } \\
\text { Ceia** }\end{array}$ \\
\hline $\begin{array}{l}\text { Leite (inclui leite } \\
\text { em pó e tipo c) }\end{array}$ & 83,6 & - & 24,0 & 7,6 \\
\hline Queijo & - & - & - & 3,8 \\
\hline logurt & - & - & - & 1,1 \\
\hline Pão & 63,8 & - & 19,3 & 35,0 \\
\hline Margarina & 61,1 & - & 4,3 & 2,5 \\
\hline Açúcar & 53,6 & 6,3 & 27,4 & 7,3 \\
\hline Café (infusão) & 50,1 & - & 3,2 & 4,7 \\
\hline Biscoito (doces e salgados) & 9,6 & - & 4,3 & 2,5 \\
\hline Bolo & 6,3 & 0,7 & 7,4 & 1,8 \\
\hline Geléia & 0,8 & - & - & - \\
\hline Arroz & - & 85,7 & 22,9 & 21,3 \\
\hline Feijão & - & 79,0 & 8,2 & 6,9 \\
\hline M acarrão & - & 16,7 & 21,7 & 2,1 \\
\hline Fubá & - & 5,7 & 6,5 & - \\
\hline Batata & - & 21,7 & 13,9 & 3,8 \\
\hline Maisena & - & - & 7,3 & - \\
\hline Pizza & - & - & - & 2,5 \\
\hline Pipoca & - & - & - & 0,8 \\
\hline \multicolumn{5}{|l|}{ Carnes } \\
\hline Bovina*** & - & 24,6 & - & 3,1 \\
\hline Aves*** & - & 41,3 & 13,9 & 5,8 \\
\hline Peixe & - & 11,4 & - & - \\
\hline Porco & - & 4,6 & - & - \\
\hline Ovos & - & 14,2 & 3,2 & 15,1 \\
\hline \multicolumn{5}{|l|}{ Embutidos } \\
\hline Salsicha & - & 9,0 & 5,3 & 4,9 \\
\hline Lingüiça & - & 1,9 & - & 6,0 \\
\hline Mortadela & - & - & - & 11,1 \\
\hline Presunto & - & - & - & 1,4 \\
\hline \multicolumn{5}{|l|}{ Hortaliças (cozidas) } \\
\hline Brócolis & - & 7,4 & - & - \\
\hline Couve & - & 3,8 & 8,3 & 0,7 \\
\hline Espinafre & - & 1,9 & - & - \\
\hline Repolho & - & 3,2 & 4,1 & - \\
\hline \multicolumn{5}{|l|}{ Hortaliças (cruas) } \\
\hline Alface & - & 37,2 & - & 3,2 \\
\hline Repolho & - & 3,2 & 4,1 & - \\
\hline Chicória & - & 3,9 & 4,1 & - \\
\hline \multicolumn{5}{|l|}{ Legumes (cozidos) } \\
\hline Chuchu & - & 4,7 & 2,0 & - \\
\hline Tomate & - & 30,1 & 8,3 & 3,1 \\
\hline Cenoura & - & 11,8 & 4,0 & - \\
\hline Beterraba & - & 3,1 & - & - \\
\hline Pimentão & - & 0,6 & - & - \\
\hline Abobrinha & - & 1,5 & 2,0 & - \\
\hline \multicolumn{5}{|l|}{ Legumes (crus) } \\
\hline Tomate & - & 7,8 & 4,8 & 0,6 \\
\hline Pepino & - & 1,7 & - & - \\
\hline
\end{tabular}

Tabela 2

Freqüência percentual de determinados alimentos nas refeições do dia. Americana, 1994. 
Tabela 2 (continuação)

\begin{tabular}{|c|c|c|c|c|}
\hline \multirow[t]{2}{*}{ Alimentos } & \multirow[b]{2}{*}{ Desjejum* } & \multicolumn{3}{|c|}{ Refeição } \\
\hline & & $\begin{array}{c}\text { Cieps } \\
\text { Almoço* }\end{array}$ & J antar* & $\begin{array}{c}\text { Domiciliares } \\
\text { Ceia*** }\end{array}$ \\
\hline Óleo de soja & - & 80,1 & 20,0 & - \\
\hline Maionese & - & 3,4 & - & 2,0 \\
\hline \multicolumn{5}{|l|}{ Frutas } \\
\hline Laranja & - & 29,2 & 5,4 & 2,6 \\
\hline Banana & - & 25,1 & 1,7 & 2,9 \\
\hline Abacate & - & 5,0 & 5,1 & 2,0 \\
\hline Melancia & - & 4,9 & - & - \\
\hline Mamão & - & 2,1 & - & - \\
\hline Limão & - & - & 1,3 & - \\
\hline Abacaxi & - & - & 1,4 & 1,0 \\
\hline Pudim (chocolate e caramelo) & - & 4,9 & 1,0 & - \\
\hline Gelatina & - & 5,3 & 12,8 & - \\
\hline Chocolate & - & - & - & 6,5 \\
\hline Chá & - & - & - & 1,8 \\
\hline Refrigerante & - & - & - & 13,3 \\
\hline Suco de frutas (uva) & - & - & - & 1,7 \\
\hline Sorvete & - & - & - & 2,8 \\
\hline Garapa & - & - & - & 0,6 \\
\hline Chicletes/balas/drops & - & - & - & 1,1 \\
\hline
\end{tabular}

* Refeições dos CIEPs.

** Refeições domiciliares e/ou em outros estabelecimentos.

*** Inclui miúdos.

Obs.: Os traços (-) significam que o alimento na refeição não foi observado.

Não se espera uma relação muito forte entre a adequação do consumo alimentar e a renda familiar per capita dos escolares, uma vez que o atendimento nutricional dos CIEPs é homogêneo. Entretanto, verifica-se que a renda familiar per capita afeta significativamente a percentagem de atendimento das recomendações de energia e vários nutrientes. Isso se explica basicamente pelo fato de os escolares de famílias mais ricas já terem previamente maior estatura e peso e também por parte da alimentação ainda ser obtida no próprio domicílio.

\section{Discussão}

Observou-se que há apreciável presença da carne de frango na principal refeição servida nos CIEPs (almoço) e nas ceias. Os resultados parecem ser concordantes com as evidências sobre a evolução do consumo da ave no Brasil: aumento anual de 2,3 kg per capita em 1970 para $16,0 \mathrm{~kg}$ em 1992, confirmando uma variação positiva ao longo do tempo e indicando a generalização de seu consumo e a consolidação de um novo hábito alimentar entre a população de diferentes níveis de renda (Silva \& Fabrini, 1994).
Possivelmente, a carne de frango destacase entre os demais tipos em função de fatores como: al ta aceitabilidade entre a população e o preço do produto (Bacchi, 1994) que, nas últimas três décadas, sofreu drástica redução (aproximadamente 70\% de redução real). O fator custo torna o produto bastante acessível, tanto para a prefeitura municipal, responsável pelo financiamento do programa de alimentação escolar, como para significativa parcela das famílias de Americana.

Quanto à presença do feijão, o reduzido percentual $(6,9 \%)$ observado nas refeições domiciliares parece refletir as considerações apresentadas por Hoffmann (1995) sobre o declínio do consumo de feijão em áreas urbanas, ao longo do tempo. Segundo o autor, um dos condicionantes da queda poderia estar associado ao preço real em relação a outros produtos. No entanto, o autor demonstra, por meio da análise gráfica da série de preços (deflacionados pelo índice de preços de alimentos da Fundação Instituto de Pesquisas Econômicas da USP), que não houve tendência de crescimento real.

A ocorrência da menor freqüência do consumo de feijão (em nível doméstico) pode estar associada à urbanização, que levou maior número de mulheres para o mercado de trabaIho. Senauer et al. (1986) demonstraram que, na área urbana do Sri Lanka, o crescimento do custo de oportunidade do trabalho doméstico das mulheres aumenta a demanda por pão, no caso, em detrimento da demanda do arroz, alimento até então considerado tradicional na dieta daquela população, como o feijão o é para os brasileiros.

Também deve-se lembrar que a cocção do feijão exige, além do tempo, despesas adicionais com o gás de cozinha, havendo, portanto, custo monetário explícito.

Examinando os dados relativos à participação do pão nas refeições domiciliares, nota-se que o percentual verificado é superior ao do consumo de arroz (21,3\%) e feijão (6,9\%).

Uma das explicações plausíveis para a maior presença do pão na última refeição do dia é o fato de tanto o arroz, quanto o feijão exigirem maior tempo de cocção, o que dificulta o consumo em sociedades urbanizadas, onde as mulheres participam cada vez mais do mercado, tendendo a reduzir o tempo dedicado ao trabalho doméstico.

Outras interpretações para o fenômeno são apresentadas por Harvey (1989), que destaca as modificações sociológicas subjacentes à passagem da modernidade à pós-modernidade. $\mathrm{O}$ autor argumenta que a aceleração no tempo de giro de capital, a flexibilidade das práticas de 
Tabela 3

Adequação média do consumo de energia e nutrientes ocorrido nos CIEPs, Americana, 1994.

\begin{tabular}{|c|c|c|c|c|c|c|c|c|c|c|c|}
\hline $\begin{array}{l}\text { Idade } \\
\text { (anos) }\end{array}$ & $\mathrm{N} *$ & $\%$ & Energia & Proteína & Vitamina $\mathrm{A}$ & Tiamina & Riboflavina & Niacina & $\begin{array}{l}\text { Ácido } \\
\text { ascórbico }\end{array}$ & Cálcio & Ferro \\
\hline$<8$ & 43 & 17,6 & $\begin{array}{l}65 \\
(17)\end{array}$ & $\begin{array}{c}118,2 \\
(30,0)\end{array}$ & $\begin{array}{l}110,3 \\
(45,3)\end{array}$ & $\begin{array}{c}102,9 \\
(38,8)\end{array}$ & $\begin{array}{c}137,2 \\
(80,0)\end{array}$ & $\begin{array}{l}82,6 \\
(32,6)\end{array}$ & $\begin{array}{l}272,2 \\
(89,8)\end{array}$ & $\begin{array}{c}105,1 \\
(24,9)\end{array}$ & $\begin{array}{c}71,9 \\
(26,8)\end{array}$ \\
\hline $8 \vdash 9$ & 39 & 16,0 & $\begin{array}{l}68 \\
(20)\end{array}$ & $\begin{array}{c}122,6 \\
(34,9)\end{array}$ & $\begin{array}{c}151,6 \\
(66,3)\end{array}$ & $\begin{array}{c}99,0 \\
(37,6)\end{array}$ & $\begin{array}{c}128,0 \\
(68,3)\end{array}$ & $\begin{array}{c}84,5 \\
(37,8)\end{array}$ & $\begin{array}{c}285,1 \\
(124,3)\end{array}$ & $\begin{array}{c}109,5 \\
(27,0)\end{array}$ & $\begin{array}{c}82,2 \\
(31,1)\end{array}$ \\
\hline $9 \vdash 10$ & 37 & 15,2 & $\begin{array}{l}59 \\
(20)\end{array}$ & $\begin{array}{c}117,1 \\
(42,6)\end{array}$ & $\begin{array}{c}139,4 \\
(82,1)\end{array}$ & $\begin{array}{c}93,5 \\
(32,1)\end{array}$ & $\begin{array}{c}114,2 \\
(53,2)\end{array}$ & $\begin{array}{c}75,9 \\
(29,4)\end{array}$ & $\begin{array}{c}300,3 \\
(132,8)\end{array}$ & $\begin{array}{c}110,7 \\
(33,0)\end{array}$ & $\begin{array}{c}81,1 \\
(27,6)\end{array}$ \\
\hline $10 \vdash 11$ & 35 & 14,3 & $\begin{array}{l}62 \\
(24)\end{array}$ & $\begin{array}{c}122,8 \\
(52,0)\end{array}$ & $\begin{array}{c}120,4 \\
(76,7)\end{array}$ & $\begin{array}{c}99,3 \\
(39,5)\end{array}$ & $\begin{array}{c}125,3 \\
(72,1)\end{array}$ & $\begin{array}{c}83,6 \\
(43,2)\end{array}$ & $\begin{array}{c}334,9 \\
(174,6)\end{array}$ & $\begin{array}{l}88,0 \\
(24,3)\end{array}$ & $\begin{array}{c}90,3 \\
(38,1)\end{array}$ \\
\hline $11 \vdash 12$ & 34 & 13,9 & $\begin{array}{l}67 \\
(31)\end{array}$ & $\begin{array}{c}122,1 \\
(63,8)\end{array}$ & $\begin{array}{c}118,3 \\
(88,7)\end{array}$ & $\begin{array}{c}112,5 \\
(62,0)\end{array}$ & $\begin{array}{c}133,1 \\
(74,3)\end{array}$ & $\begin{array}{c}92,5 \\
(54,2)\end{array}$ & $\begin{array}{l}308,0 \\
(154)\end{array}$ & $\begin{array}{c}84,8 \\
(29,2)\end{array}$ & $\begin{array}{c}104,7 \\
(56,7)\end{array}$ \\
\hline $12 \vdash 13$ & 31 & 12,7 & $\begin{array}{c}64 \\
(33)\end{array}$ & $\begin{array}{c}121,2 \\
(69,0)\end{array}$ & $\begin{array}{c}151,0 \\
(143,1)\end{array}$ & $\begin{array}{c}115,7 \\
(72,8)\end{array}$ & $\begin{array}{c}134,7 \\
(102,2)\end{array}$ & $\begin{array}{c}94,3 \\
(63,3)\end{array}$ & $\begin{array}{c}339,6 \\
(182,9)\end{array}$ & $\begin{array}{c}87,1 \\
(39,7)\end{array}$ & $\begin{array}{c}118,0 \\
(74,1)\end{array}$ \\
\hline$\geq 13$ & 25 & 10,3 & $\begin{array}{l}56 \\
(21)\end{array}$ & $\begin{array}{c}101,6 \\
(42,6)\end{array}$ & $\begin{array}{c}84,7 \\
(61,3)\end{array}$ & $\begin{array}{c}89,2 \\
(39,5)\end{array}$ & $\begin{array}{c}101,2 \\
(59,1)\end{array}$ & $\begin{array}{c}76,0 \\
(39,1)\end{array}$ & $\begin{array}{c}227,2 \\
(125,6)\end{array}$ & $\begin{array}{c}72,3 \\
(21,7)\end{array}$ & $\begin{array}{c}47,3 \\
(24,8)\end{array}$ \\
\hline
\end{tabular}

*N = número de crianças observadas.

Obs.: Os números entre parênteses são os desvios padrões.

Tabela 4

Adequação média do consumo de energia e nutrientes ocorrido no domicílio, Americana, 1994.

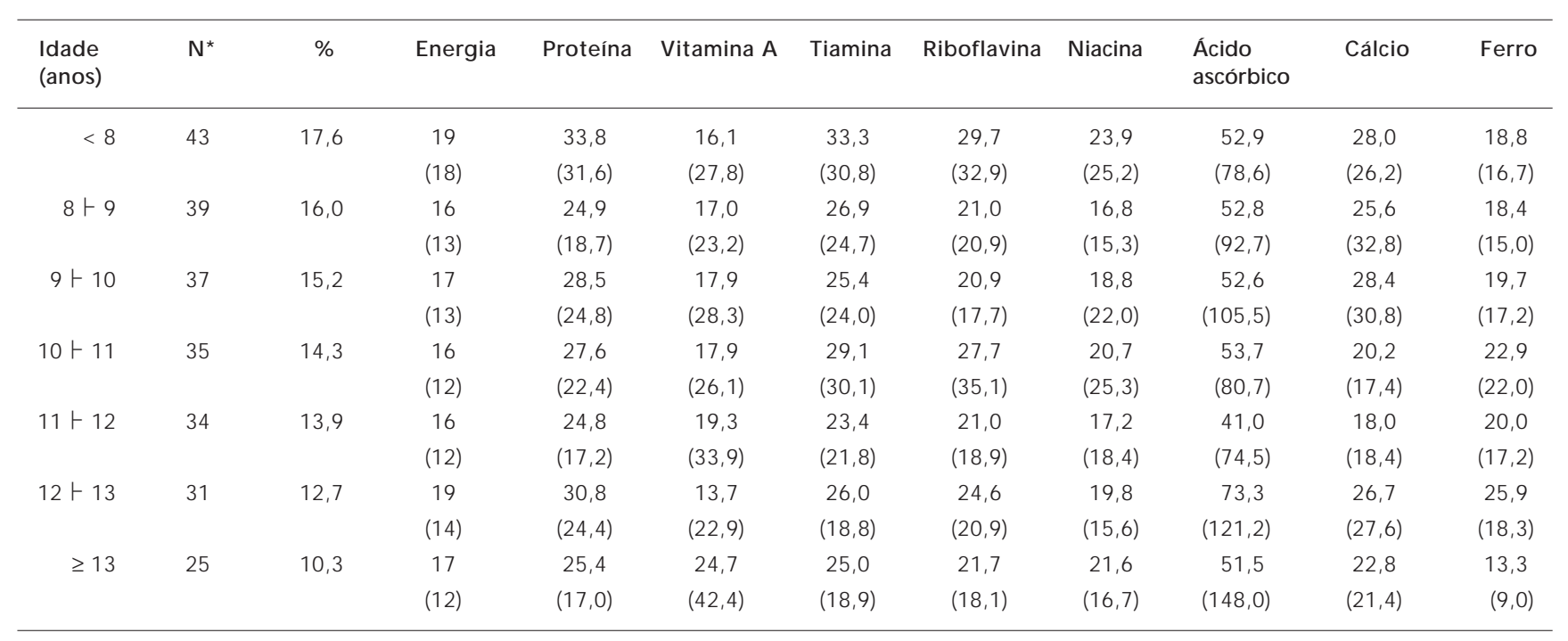

*N = número de crianças observadas.

O bs.: Os números entre parênteses são os desvios padrões.

trabalho, o avanço do conhecimento científico, administrativo burocrático e racional, vital para o progresso da produção e do consumo capitalista, traz conseqüências importantes principalmente para as práticas alimentares no meio urbano. Desse modo, o curto tempo que as pessoas têm para o ato de se alimentar transforma a pressa num dos traços visíveis da caracterização do modo de comer em regiões altamente urbanizadas, com o abreviamento do ritual alimentar em suas diferentes fases, da preparação ao consumo.

Deve-se ressaltar que Lerner (1994), estudando o consumo alimentar de jovens da região metropolitana de São Paulo, verificou que os mesmos estão substituindo o jantar tradi- 
cional por lanches, cuja composição nem sempre satisfaz os requisitos de uma al imentação adequada.

As hortaliças aparecem com freqüência maior nas refeições distribuídas no CIEPs, destacando-se que a maioria delas são habitualmente consumidas cozidas. Este fato pode contribuir para que ocorram perdas de ácido ascórbico durante a cocção. Desse modo, a preocupação com a preservação de nutrientes, dentre os quais o ácido ascórbico, deve ser constante nos serviços de alimentação. De acordo com Silva (1990), a perda de ácido ascórbico pela manipulação desde a colheita até o seu consumo é exacerbada no serviço de alimentação, uma vez que exige descongelamento e manutenção em temperatura elevada por longos intervalos de tempo.

Observou-se (Tabelas 3 e 4) que a ingestão calórica constitui-se maior problema para os escolares mais velhos.

Situação oposta é observada para a proteína. Note-se que somente as refeições dos CIEPs seriam suficientes para atender às recomendações para todos os grupos de idade analisados.

Estes achados somam-se aos de outros autores que, estudando os programas de alimentação escolar operacionalizados, de forma descentralizada, no Estado de São Paulo, concluíram que a principal falha dos mesmos é favorecer refeições de valor energético abaixo dos padrões propostos (Nutti, 1986; Cesar, 1990; Silva, 1991; Salay \& Carvalho, 1995).

Ainda com relação ao atendimento calórico e protéico é pertinente destacar que, mesmo entre população de baixa renda, Rivera \& Rivera (1986) verificaram que o valor nutricional da dieta consumida por escolares paraibanos, em relação ao recomendado, representava em média $66,0 \%$ das calorias e $96,0 \%$ das proteínas. Os autores chamam a atenção para os aspectos de insuficiência e desequilíbrio do consumo alimentar da população estudada.

Estudo recente de Souza \& Marinho (1996) também mostrou elevado consumo protéico (173,9\%) e apenas $79,9 \%$ do recomendado de energia entre escolares do Município de Manaus.

Os resultados obtidos por essas pesquisas são coerentes com as mudanças detectadas no padrão alimentar nos últimos 26 anos, tanto para populações urbanas do Sudeste, quanto para as do Norte e Nordeste do país. De acordo com Mondini \& Monteiro (1994), há uma tendência generalizada de maior consumo de proteínas.

No que tange às vitaminas, destaca-se a surpreendente adequação da dieta com relação ao ácido ascórbico.
É possível verificar que a contribuição das refeições dos CIEPs superam em mais de duas vezes as recomendações para todas as faixas etárias. Tal situação pode ser atribuída em parte à disponibilidade diária de hortaliças e frutas (particularmente a laranja) nas refeições da escola.

Deve-se considerar, no entanto, que o cálculo do valor nutricional baseia-se em tabela cujos dados se referem aos alimentos crus, não levando em conta as perdas acarretadas pela cocção. No caso das refeições servidas no âmbito das escolas, esse fato pode ocorrer, considerando-se que as sopas servidas aos escolares são freqüentemente preparadas à base de hortaliças e submetidas a processos de cocção por tempo prolongado.

É importante ressaltar que o ácido ascórbico é considerado elemento essencial para o aproveitamento do ferro alimentar. A biodisponibilidade do ferro da dieta depende principalmente da presença de carnes e ácido ascórbico nas refeições. De acordo com Halberg (1981), 50 mg de ácido ascórbico, proveniente de frutas ou vegetais, são suficientes para duplicar a absorção de ferro não-heme presente em uma mesma refeição. Tal situação é facilmente identificada na pauta alimentar das crianças, principalmente quando se analisa a freqüência de citações dos referidos itens nas refeições oferecidas nos CIEPs.

Com relação à adequação do consumo de ferro, o resultado verificado para os escolares mais velhos (adolescentes) merece atenção, pois os mesmos são mais susceptíveis à anemia devido ao rápido crescimento do esqueleto, do volume sangüíneo e da massa muscular, o que exige incremento do volume de alimentos fontes de ferro.

Vale destacar que os resultados obtidos nesta pesquisa são concordantes com aqueles obtidos por Lerner (1994), que, estudando a prática alimentar de estudantes (5a à 8a série) de escolas públicas, verificou que o consumo de ferro total revelou-se inadequado para a maior parte da população estudada.

Julgou-se pertinente uma exploração mais detalhada sobre as diferenças de adequação nutricional da dieta entre as faixas etárias. Para tanto, foi feita uma análise de variância da percentagem de atendimento das recomendações nutricionais para energia e para cada um dos nutrientes, considerando as sete faixas etárias como tratamentos. As médias por faixa etária foram comparadas através do teste de Tukey. Entre os resultados obtidos, cabe ressaltar o fato de que a percentagem de atendimento médio para os escolares com 13 anos ou mais de 
idade (adolescentes) é quase sempre a mais baixa. Para as vitaminas A e C, cálcio e ferro, a percentagem de atendimento para crianças mais velhas se mostrou significativamente menor do que a de outras faixas etárias (ao nível de significância de 5\%).

Tal situação possivelmente decorre do fato de a adolescência se caracterizar como uma etapa do desenvolvimento humano marcada por acentuadas mudanças. Trata-se de uma fase crítica para o desenvolvimento de atividades e comportamentos relacionados especialmente à dieta, ao exercício físico e ao consumo de bebidas alcoólicas.

Vale destacar que, no tocante às refeições domiciliares, proporção substancial de escolares afirmou não consumir nenhum alimento. $\mathrm{O}$ impacto de tal comportamento é invariavelmente negativo, na medida em que pode predispor as crianças a terem déficits energéticos e nutricionais.

Gambardella (1996) alerta para a susceptibilidade dos adolescentes às deficiências nutricionais específicas e para o comportamento displicente com relação às conseqüências de suas práticas alimentares para a vida futura.

Deve-se ressaltar, também, que a adolescência se constitui um período em que ocorrem, com extrema facilidade, mudanças e incorporação de novos hábitos na alimentação.

Grazini (1996) destaca que países desenvolvidos, atentos ao referido comportamento, preocupam-se com a formação ou modificação de hábitos alimentares durante a adolescência, em razão do desenvolvimento de doenças decorrentes do excesso ou déficit de consumo alimentar.

\section{Comentários finais}

O consumo alimentar (alimentos consumidos nos CIEPs e em nível domiciliar) revelou-se deficiente em energia, evidenciando o problema relativo à quantidade dos al imentos ingeridos e não à qualidade. Tal constatação merece atenção pelo fato de que as crianças permanecem aproximadamente dez horas na unidade em jornada de aulas e atividades recreativas, e conseqüentemente sem alternativas para consumo de alimentos.

Cumpre ressaltar que, sendo o valor calórico insuficiente, a proteína será em parte utilizada como fonte energética e, portanto, tornase antieconômico atender às recomendações de calorias através de alimentos que representam boa fonte de proteínas.
Uma das maneiras de corrigir tal falha é incluir alimentos ricos em hidratos de carbono nas refeições dos escolares. Trata-se de nutriente energético que libera energia mais prontamente, contribuindo, assim, para a elevação do valor energético das dietas.

Quanto ao teor de vitaminas, duas evidências importantes: o expressivo consumo de alimentos fontes de vitamina $\mathrm{C}$ e a menor adequação em relação à niacina. Os resultados satisfatórios quanto ao ácido ascórbico devem ser atribuídos à presença de frutas cítricas (principalmente a laranja) servidas com elevada freqüência nas refeições das quatro escolas.

É desejável manter os percentuais de atendimento do ácido ascórbico devido a sua valiosa contribuição para potencializar a absorção principalmente do ferro não-heme da dieta e sua provável perda durante processo de preparo dos alimentos.

O aumento do conteúdo de niacina nas refeições pode ser implementado com a inclusão, com maior freqüência, do peixe, considerado fonte rica dessa vitamina. O uso de ovos nas preparações também é um recurso a ser considerado, pois mesmo contendo pequenas quantidades de niacina, são excelentes fontes do triptofano (precursor da niacina).

No que se refere ao ferro, os resultados apontam para a necessidade de aumentar a oferta de alimentos fontes desse mineral nas refeições oferecidas aos escolares, contribuindo, assim, para evitar deficiências que possivelmente possam predispor o grupo de maior idade à anemia ferropriva.

Enfatiza-se, também, a necessidade de orientar os escolares, sobretudo os de idades mais elevadas, no sentido de que não substituam alimentos como, por exemplo, o feijão, principalmente na refeição consumida em nível domiciliar, por lanches cujos valores calórico e nutricional invariavelmente não atendem às recomendações preconizadas para o grupo.

Esse estudo mostra que as refeições fornecidas pelos CIEPs constituem parte fundamental do consumo alimentar dos escolares que os freqüentam. Com pouca despesa adicional seria, sem dúvida, possível cobrir as deficiências constadas, particularmente no total de energia e de ferro. É claro, finalmente, que o consumo alimentar desses escolares deve ser complementado por refeição feita no seu domicílio, que ainda fornece parcela substancial dos nutrientes. Os escolares e seus pais devem ser orientados para que as refeições em casa tenham a melhor qualidade possível, dentro das limitações impostas pelo seu reduzido rendimento. 


\section{Agradecimentos}

A autora agradece os valiosos comentários e sugestões de um parecerista anônimo.

\section{Referências}

BACCHI, M. R. P., 1994. Previsão de Preços de Bovino, Suíno e Frango com Model os de Séries Temporais. Tese de Doutorado, Piracicaba: Escola Superior de Agricultura "Luiz de Queiroz", Universidade de São Paulo.

CESAR, A. T., 1990. O Uso do Ácido Ascórbico no Controle da Deficiência deFerro Utilizando a Estrutura do Programa de Merenda Escolar. Dissertação de Mestrado, São Paulo: Faculdade de Saúde Pública, Universidade de São Paulo.

FIBGE (Fundação Instituto Brasileiro de Geografia e Estatística), 1977. Tabela de Composi ção de Alimentos. Rio de Janeiro: FIBGE.

FIBGE (Fundação Instituto Brasileiro de Geografia e Estatística), 1989. Crianças e Adol escentes: Indicadores Sociais. Rio de Janeiro: FIBGE.

GAM BARDELLA, A. M. D., 1996. Adolescentes, Estudantes de Período Noturno: Como se Alimentam e Gastam Suas Energias. Tese de Doutorado, São Paulo: Faculdade de Saúde Pública, Universidade de São Paulo.

GRAZINI, J. T., 1996. Analogia entreComerciais deAlimentos e Hábito Ali mentar de Adol escentes. Dissertação de Mestrado, São Paulo: Escola Paulista de Medicina, Universidade Federal de São Paulo.

HALBERG, L., 1981. Bioavailability of dietary iron in man. Annual Review, 1:123-147.

HARVEY, D., 1989. Condição Pós-Moderna. São Paulo: Loyola.

HOFFMANN, R., 1995. A diminuição do consumo de feijão no Brasil. Estudos Econômicos, 25(2): 189201.

LERNER, B. R., 1994. A alimentação e a anemia carencial em adolescentes. Tese de Doutorado, São Paulo: Faculdade de Saúde Pública, Universidade de São Paulo.

MADDEN, J. P.; GOODM AN, S. J. \& GUTHRIE, H. A., 1976. Validity of the 24-hs. recall: analysis of data obtained from elderly subjects. Journal American Dietetic Association, 68:143-147.

MARTINS, I. S. \& HIDALGO, C. P., 1983. Recomendações Nutricionais para a População Brasileira. Brasília: Inan (Instituto Nacional de Alimentação e Nutrição).

MONDINI, L. \& MONTEIRO, C. A., 1994. Mudanças no padrão de alimentação da população urbana brasileira (1962-1988). Revista de Saúde Pública, 28:433-439.

NUTTI, M. R., 1986. Análise dos Sistemas de Alimentação Escolar em 5 Municípios do Estado de São Paulo. Dissertação de Mestrado, Campinas: Faculdade de Engenharia de Alimentos, Universidade Estadual de Campinas.
PIPITONE, M. A. P., 1991. Programa de Promoção Integral da Criança - PROFIC - da Proposta Teórica à Implementação: O Caso de Piracicaba, SP. Dissertação de Mestrado, São Carlos: Faculdade de Educação, Universidade Federal de São Carlos.

RIBEIRO, D., 1986. O Livro dos CIEPs. Rio de Janeiro: Bloch Editores.

RIVERA, M. A. A. \& RIVERA, F. A. C., 1986. Perfil nutricional da dieta de escolares e pré-escolares pertencentes à população de baixa renda. Centro de Ciências da Saúde. Universidade Federal da Paraiba, 81:12-14.

SALAY, E. \& CARVALHO, J. F., 1995. Avaliação do programa de merenda escolar do Município de Campinas, Brasil. Archivos Latinoamericanos de Nutrición, 45:167-171.

SEADE (Fundação Sistema Estadual de Análise de Dados), 1991. Anuário Estatístico do Estado de São Paulo. São Paulo: Seade.

SEADE (Fundação Sistema Estadual de Análise de Dados), 1993. Perfil Municipal (1980-1991). Região Administrativa de Campinas. São Paulo: Seade.

SENAUER, B.; SAHN, D. \& ALDERMAN, H., 1986. The effect of the value of the time on food consumption patterns in developing countries: evidence from Sri Lanka. American Agricultural Economics, 68:920-927.

SILVA, L. F. \& FABRINI, L. C., 1994. Complexo avícola e questões sobre hábito alimentar. Caderno de Debate, 2:41-61.

SILVA, M. E. P., 1990. Teores deVitamina C em Alimentos de Consumo Habitual na Região de São Paulo. Dissertação de Mestrado, São Paulo: Faculdade de Ciências Farmacêuticas, Universidade de São Paulo.

SILVA, M. V., 1991. Contribuição do Programa de Merenda Escolar - Ciclo Básico para as Recomendações Nutricionais de Escolares da Cidade de Piracicaba. Dissertação de Mestrado, São Paulo: Faculdade de Saúde Pública, Universidade de São Paulo.

SOUZA, A. M. \& MARINHO, H. A., 1996. A Avaliação Nutricional em Escolares de la à 4a Série na Periferia (Zona Leste) da Cidade de Manaus. IV Congresso Nacional da Sociedade Brasileira de Alimentação e Nutrição. São Paulo: SBAN. 